\title{
ALELOPATIA DE ACÍCULAS DE PÍNUS NA GERMINAÇÃO E DESENVOLVIMENTO DE PLÂNTULAS DE MILHO, PICÃO PRETO E ALFACE
}

\author{
ALLELOPATHY OF PINE NEEDLES ON THE GERMINATION AND \\ DEVELOPMENT OF CORN, LETTUCE AND BEGGARTICK
}

\author{
Laércio Ricardo SARTOR ${ }^{1}$; Leo LOPES ${ }^{2}$; Thomas Newton MARTIN ${ }^{3}$; Sidney ORTIZ $^{4}$ \\ 1. Professor, Doutor, Coordenação de Agronomia da Universidade Tecnológica Federal do Paraná, Campus Dois Vizinhos, PR, Brasil. \\ laerciosartor@hotmail.com; 2. Especialista em Controle Biológico, Universidade Tecnológica Federal do Paraná, Campus Dois \\ Vizinhos, PR, Brasil; 3. Professor, Doutor, Departamento de Fitotecnia da Universidade Federal de Santa Maria, RS, Brasi; 4. Mestre \\ em Zootecnia, Universidade Tecnológica Federal do Paraná, Campus Dois Vizinhos, PR, Brasil.
}

RESUMO: Os sistemas agrosilvipastoris estão ampliando os espaços ocupados e ganhando novos adeptos, tendo em vista ampliações produtivas nas mesmas áreas. Porém algumas questões, como efeitos alelopáticos de algumas culturas, nesse caso o pinus, ainda são pouco conhecidas. Objetivou-se com esse trabalho avaliar o efeito alelopático do extrato aquoso de acículas de Pinus taeda na germinação e no desenvolvimento de plântulas de alface, picão-preto e milho. $\mathrm{O}$ experimento foi conduzido no delineamento inteiramente casualizado, com os tratamentos distribuídos em um bifatorial (2x5), onde: condições das acículas (verdes e secas) x concentrações dos extratos $(0,25,50,75$ e 100\%), em quatro repetições sob condições de temperatura, umidade e luminosidade controladas. As avaliações foram realizadas no tempo em intervalos regulares de 24 horas, de 0 a 144 horas. Avaliou-se a germinação, velocidade média da germinação, comprimento das radículas e epicótilos da alface, picão-preto e milho. Extratos a base de acícula verde afetou significativamente as variáveis, onde o efeito aumentava conforme aumentava a concentração, sendo o efeito mais perceptível no picão-preto. Já no extrato a base de acículas seca de pínus, houve resultados mínimos quando comparados a testemunha.

PALAVRA-CHAVE: Bidens pilosa. Lactuca sativa. Pinus taeda. Zea mays.

\section{INTRODUÇÃO}

A eminente necessidade de se aumentar a produção de alimentos, visto a demanda com aumento da população, traz consigo a característica de atividades agrícolas mais sustentáveis, especialmente em relação ao ambiente. A fim de maximizar a produção por área, crescem os incentivos de sistemas de produção integrada, como os sistemas agroflorestais, onde é cultivando espécies arbóreas em conjunto à produção de grãos (milho, soja, feijão).

Nesse sentido, o Pinus taeda tem demonstrado efeito alelopático sobre o desenvolvimento inicial de outras culturas (SARTOR et al., 2009). O que traria insucesso ao uso dessa espécie arbórea quando em consórcio com culturas de lavoura como o milho. No entanto, os aleloquímicos, compostos químicos responsáveis pela alelopatia, podem ser diferentes entre espécies arbóreas e apresentar variação de ação na comunidade vegetal. Ferreira et al. (2007) verificaram redução da velocidade de germinação de picão-preto em extrato Eucalypto citriodora, porém, não obtiveram interferência de extrato de Pinus eliotti sobre picão-preto e alface. Alguns resultados importantes com arbóreas são destacados por Silva et al. (2012) sugerindo que existem a presença de substâncias aleloquímicas nas amostras de solo coletadas sob a copa de Copaifera langsdorffii. Já Silveira et al. (2012) destacam que houve efeito alelopático negativo dos extratos com maiores concentrações sob o desenvolvimento de plântulas de alface, com inibição do crescimento da raiz e do hipocótilo/coleóptilo, e alta percentagem de plântulas anormais nas duas temperaturas de extração.

Em um dossel de plantas cultivadas é interessante verificarmos a redução da velocidade de germinação das plantas daninhas em relação às plantas cultivadas. Nesse sentido, a cultura, milho, por exemplo, poderia estabelecer-se mais rapidamente no ambiente, reduzindo-se assim o poder competitivo das plantas daninhas (Urochloa plantaginea, por exemplo).

Da mesma forma, partes da planta como folha, casca e galhos podem apresentar diferentes efeitos alelopáticos, dependendo da planta receptora, como demonstra o trabalho de Souza Filho et al. (2010) ao avaliar extratos de espécies de Copaifera (Leguminosae - Caesalpinioideae) sobre plantas daninhas. Também, o estágio vegetativo com que se encontra a planta ou a concentração do componente alelopático, tem apresentado diferença 
de ação inibitória a outras plantas. Sartor et al. (2009) observaram menor velocidade de germinação de Avena strigosa em extrato aquoso de acícula verde de Pinus taeda, e nenhum efeito quando com extrato de acícula seca (senescida ou no formato de serrapilheira).

Contudo, a descoberta de substâncias alelopáticas pode servir de base para o desenvolvimento de produtos a serem usados no controle, na agricultura, de plantas concorrentes, pragas ou doenças. Estudos relatam a presença de substâncias aleloquímicas de espécies arbóreas, os quais inibem ou interferem na germinação e desenvolvimento inicial de plantas daninhas como Euphorbia heterophylla, Ipomoea grandifolia, Echinochloa crus-galli e Bidens pilosa (INOUE et al., 2010; FORMAGIO et al., 2011; GRISI et al., 2012). Também Mauli et al. (2009) verificaram efeito alelopático de extrato aquoso de Leucaena leucocephala sobre Sida rhombifolia, Ipomoea grandifolia e Bidens pilosa. Sobretudo, os mesmos extratos não interferiram negativamente no desenvolvimento inicial da cultura da soja.

Dessa forma, objetivou-se avaliar o potencial alelopático dos extratos feitos à base de acícula verde e seca de Pinus taeda, no desenvolvimento e na germinação das sementes de alface, milho e picão-preto.

\section{MATERIAL E MÉTODOS}

O extrato das acículas de pínus foi feito com acículas de Pinus taeda, em diferentes estádios. O primeiro estádio consistiu na coleta de acículas secas (AS), naturalmente caídas ao solo, sem sinal aparente de decomposição. E o segundo estádio continha acículas coletadas ainda verdes (AV), retiradas diretamente da árvore de um mesmo reflorestamento de Pinus taeda. O reflorestamento possuía cerca de oito anos de cultivo, na região sudoeste do Paraná, clima classificado como Cfa, segundo Köppen (MORENO, 1961) e solo classificado como Latossolo vermelho distroférrico (EMBRAPA, 2006). O delineamento experimental foi inteiramente casualizado, com os tratamentos distribuídos em fatorial (estádio da acícula de pínus versus concentrações do extrato das acículas) utilizando-se quatro repetições.

Imediatamente após a colheita das acículas, obteve-se o extrato bruto (EB) para ser diluído nas diferentes concentrações. Para o EB foram triturados $150 \mathrm{~g}$ de acículas AV e $150 \mathrm{~g}$ de acícula AS, com $44 \%$ e $87,5 \%$ de massa seca, respectivamente, em $500 \mathrm{~mL}$ de água destilada, com liquidificador, durante cinco minutos. Após repouso de 10 minutos o extrato foi filtrado separando partículas maiores, seguido por filtragem a vácuo e centrifugado durante cinco minutos a $3.000 \mathrm{rpm}$. A partir do EB foram feitas diluições com água destilada para alcançar as concentrações de 0,25 , 50,75 e $100 \%$ do $\mathrm{EB}$, por meio da equação $\mathrm{C} 1 * \mathrm{Vi}=$ $\mathrm{C} 2 * \mathrm{Vf}$, onde, Vi refere-se ao volume do EB a ser adicionado na diluição, $\mathrm{C} 1$ a concentração do $\mathrm{EB}$ (100\%), C2 a concentração desejada e Vf o volume final da solução $(100 \mathrm{~mL})$, em que 0 (zero) $\%$ era a testemunha composta apenas por água destilada e $100 \%$ era o EB puro extraído após centrifugação.

Para cada uma das culturas avaliadas (milho, picão-preto e alface) foram utilizadas 36 caixas plásticas do tipo gerbox, com dimensões $10 \times 15 \mathrm{~cm}$. Foi utilizado papel filtro para forrar o fundo das caixas, depois se adicionou $5 \mathrm{ml}$ do extrato, de acordo com as concentrações do EB. Após a semeadura adicionou-se $5 \mathrm{ml}$ de água destilada para umedecer o papel, seguindo a ordem cronológica. Em cada caixa foram semeadas 16 sementes, distribuídas uniformemente em quatro fileiras com quatro unidades, desinfetadas com solução de hipoclorito de sódio a $2 \%$. As caixas com as sementes foram condicionadas em BOD e mantidas em temperatura, fotoperíodo e umidade constante. $O$ poder germinativo da semente de milho era de $90 \%$, da alface de $85 \%$ e do picão de $75 \%$, após ter sido realizado o teste de germinação no mesmo laboratório com iguais condições de temperatura, umidade e fotoperíodo. Esses valores foram usados para ajustar com base em $100 \%$ os valores de germinação obtidos no experimento.

As avaliações foram realizadas a cada 24 horas $(0,24,48,72,96,120$ e 144 horas $)$ a fim de obter a porcentagem de germinação, velocidade de germinação, comprimento de radícula e do epicótilo. Conforme Labouriau et al. (1976), foram calculadas as porcentagens de germinação, por meio da equação: $\mathrm{G} \%=(\mathrm{N} / \mathrm{A}) * 100$, em que $\mathrm{G}$ é a porcentagem de germinação; $\mathrm{N}$ é o número de sementes germinadas e $\mathrm{A}$ é o número total de sementes colocadas. Foram consideradas germinadas as sementes que apresentavam $0,1 \mathrm{~cm}$ de protrusão radicular, e as plântulas foram consideradas normais ou anormais, segundo as Regras para Análise de Sementes (BRASIL, 1992). A velocidade média de germinação foi obtida pela equação $\operatorname{IVG}=(1 / \mathrm{t})$, em que $\mathrm{t}$ é o tempo médio de germinação para germinar, determinado por $\mathrm{t}=(\Sigma$ ni*ti) / $\Sigma$ ni, sendo ni o número de sementes germinadas por dia e ti o tempo de incubação (horas).

Para verificar o comprimento e desenvolvimento da radícula e epicótilo, foram 
realizadas avaliações biométricas, medindo o comprimento $(\mathrm{mm})$ das raízes primárias e das plântulas, ou seja, a distância do colo da planta até o ápice meristemático do sistema radicular e da plântula (GATTI et al., 2004), com auxílio de uma régua milimetrada. Em cada período determinou-se a média das sementes germinadas do comprimento de radícula e comprimento do epicótilo, para cada unidade experimental. Os resultados foram submetidos à análise de variância e a estudos de regressão polinomial até terceiro grau, a $5 \%$ de probabilidade de erro e analisados pelo software SOC NTIA (EMBRAPA, 1997).

\section{RESULTADOS E DISCUSSÃO}

Foi observada interação tripla para porcentagem de germinação de sementes de milho, alface e picão-preto (Figura 1). O extrato AV proporcionou atraso na germinação e menor porcentagem de germinação de sementes das culturas, quando comparado com extrato AS. Portanto, as sementes de milho, alface e picão apresentaram maior suscetibilidade a alelopatia no extrato AV de pínus. Esse comportamento também foi observado por Sartor et al. (2009), quando as sementes de aveia preta (Avena strigosa) foram submetidas a extratos foliares de pínus em diferentes estágios de decomposição, também com maior atraso na germinação quando em extrato de acículas verdes.

A germinação do milho gerou uma superfície resposta (Figura 1) a partir de 48 horas da semeadura, quando as sementes passaram a germinar dentro do período, considerando como normal para esta cultura (FAVERO et al., 2001). Os extratos de AV apresentaram menores porcentagens de germinação das sementes de milho entre 48 e 120 horas de avaliação, caracterizando atraso na germinação. Já os tratamentos contendo extratos com AS, tiveram mais de $80 \%$ das sementes germinadas nas primeiras 48 horas da semeadura, apresentando o valor máximo de germinação a partir de 96 horas. Em extrato de AS de pínus apenas na concentração de $100 \%$ do EB houve atraso na germinação de sementes de milho, porém com menor efeito ao encontrado com AV. De acordo com Pires et al. (2001), pode-se ter um atraso significativo na geminação, mas não a inibição propriamente dita de todas as sementes avaliadas, o que também é comprovando como efeito alelopático do EB. Outros autores como Erasmo et al. (2004) e Favero et al. (2001), obtiveram resultados semelhantes na avaliação da germinação do milho, alface e outras culturas de interesse agrícola com EB de Pinus eliotti. Já Silveira et al. (2012), verificaram que o extrato aquoso de folhas de jurema preta $M$. tenuifolia extraído a $100^{\circ} \mathrm{C}$ reduziu a germinação de sementes de alface nas maiores concentrações e o extrato a $25^{\circ} \mathrm{C}$ não afetou a germinação.

A germinação das sementes de alface, quando semeadas em extrato de AV, teve porcentagem de germinação reduzida com 0 aumento da concentração do EB. Porém, quando em extrato de AS observou-se menor atraso na germinação dessas sementes (Figura 1). Em ambos os estágios de acícula (AV e AS), apenas para testemunha (composta apenas por água destilada) houve germinação total das sementes. Para qual, considerando o ajuste da percentagem de germinação conforme o poder germinativo das sementes utilizadas (valor cultural de $85 \%$ ). Ferreira e Aquila (2000) encontraram em seus resultados sensibilidade da alface por compostos químicos produzidos e liberados por parte aérea de plantas encontradas nos diferentes tipos de agroecossistemas (campos, ambientes agroflorestais e áreas de pastagens). Tais efeitos influenciaram a produtividade da cultura, comprometendo assim a resistência e/ou tolerância da alface.

A alface, para esse experimento, foi utilizada como uma planta indicativa (ALVES et al., 2004), em virtude da sensibilidade que a mesma apresenta na germinação e emergência, sendo capaz de identificar substratos ou extratos vegetais que liberam compostos aleloquímicos. Dessa forma, a utilização de acículas de pínus em cultivo de alface, como substrato, ou como cobertura morta entre as plantas, deve estar respaldada por critérios técnicos que indiquem que o substrato contendo acículas de pínus não seja mais capaz de liberar compostos alelopáticos capazes de alterar o fluxo de germinação das sementes de alface (SARTOR et al., 2009).

No que diz respeito a germinação de sementes de picão-preto, verificou-se que as menores germinações ocorreram nas maiores concentrações do EB em ambos os estágios de acícula (Figura 1). Também Rizzardi et al. (2008) observaram diminuição da germinação de sementes de picão-preto com o aumento da concentração do extrato de genótipos de canola (Brassica napus). Contudo, no estágio de AV com maior concentração do EB os valores de germinação aproximaram-se de $40 \%$, enquanto para AS os valores chegam próximos de $60 \%$ de germinação. 
A - Acícula verde

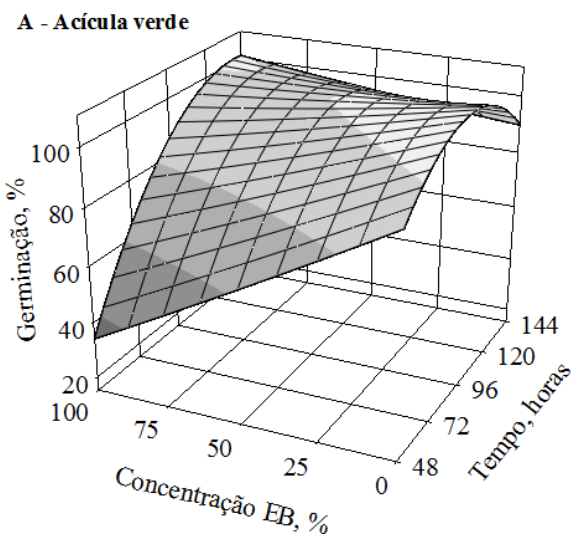

$\mathrm{AV}=37,425-0,943 * \mathrm{C}+0,00024514 * \mathrm{C}^{2}+1,51367262 * \mathrm{~T}-$ $0,00798549 * \mathrm{~T}^{2}+0,00716125 * \mathrm{C} * \mathrm{~T}$ $\mathrm{p}<0,001$ $r^{2}: 0,80$

A - Acícula verde

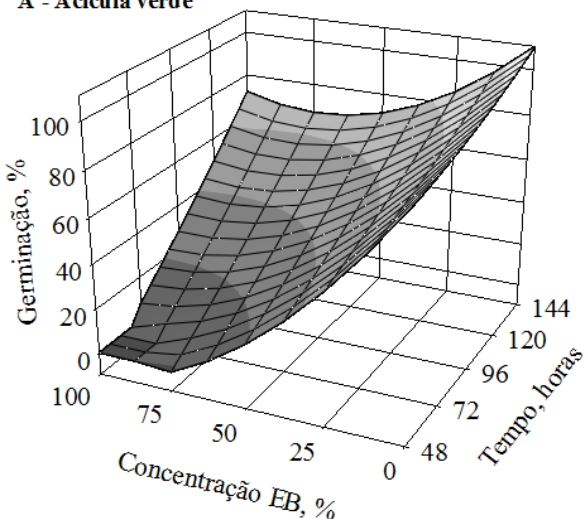

$\mathrm{AV}=84,910-2,094 * \mathrm{C}+0,007884 * \mathrm{C}^{2}+0,02344643 * \mathrm{~T}$ $-0,00104477 * T^{2}-0,00643292 * C^{*} \mathrm{~T}$ $\mathrm{p}<0,0001$ $r^{2}: 0,93$

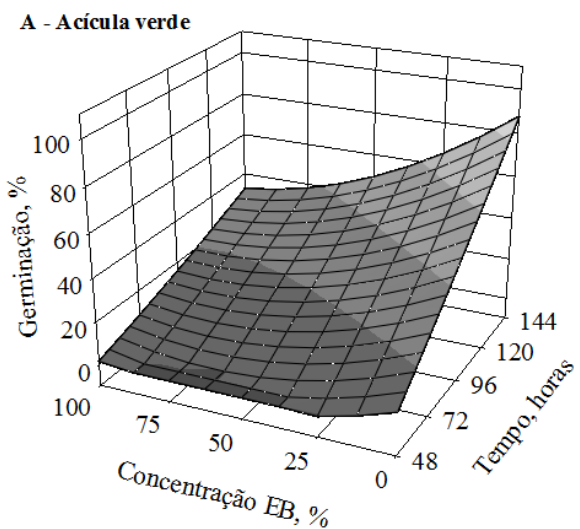

$\mathrm{AV}=-25,303-0,283 * \mathrm{C}+0,004357 * \mathrm{C}^{2}+0,70572917 * \mathrm{~T}$ $+0,00054253 * \mathrm{~T}^{2}-0,00489583 * \mathrm{C} * \mathrm{~T}$ $\mathrm{p}<0,0001$ $r^{2}: 0,91$

\section{MILHO}

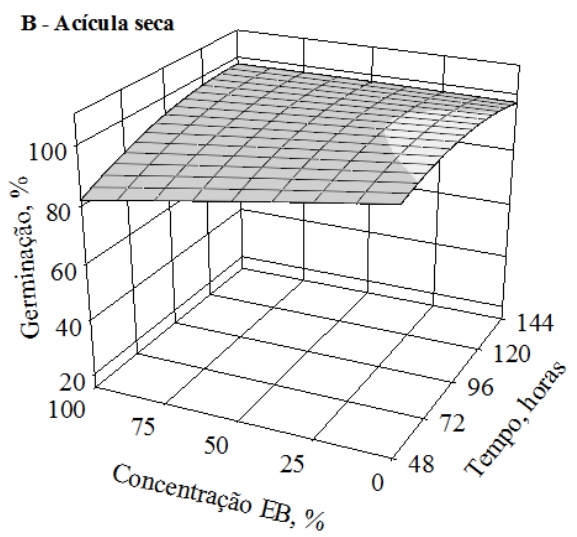

$\mathrm{AS}=86,412-0,239 * \mathrm{C}-0,00011200 * \mathrm{C}^{2}+0,34058036 * \mathrm{~T}-$ $0,00185578 * \mathrm{~T}^{2}+0,00177167 * \mathrm{C} * \mathrm{~T}$ $\mathrm{p}<0,001$

\section{ALFACE}

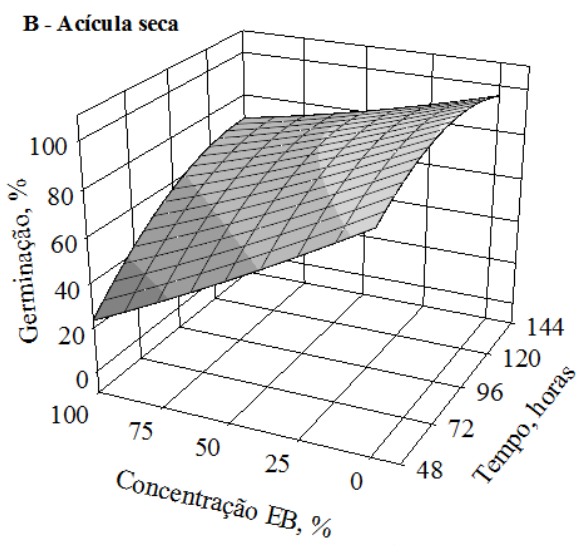

AS $=48,136-0,86822 * \mathrm{C}+0,00070857 * \mathrm{C}^{2}+1,00474107 * \mathrm{~T}$ $-0,0046906 * \mathrm{~T}^{2}+0,0036725 * \mathrm{C} * \mathrm{~T}$ $\mathrm{p}<0,0001$

$r^{2}: 0,86$

\section{PICÃO-PRETO}

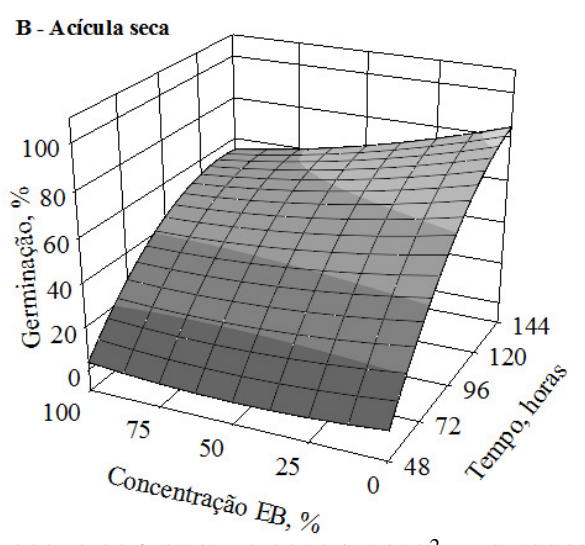

AS $=-81,803+0,00678 * \mathrm{C}+0,00135714 * \mathrm{C}^{2}+2,10342262 * \mathrm{~T}-$ $0,00658792 * \mathrm{~T}^{2}+0,003307292 * \mathrm{C} * \mathrm{~T}$ $\mathrm{p}<0,0001$ $r^{2}: 0,94$

Figura 1. Germinação percentual de sementes de milho, alface e picão-preto submetidas a concentrações $(0$, $25,50,75,100 \%)$ do extrato bruto (EB, \%) de acícula de pínus verde (A) e acícula de pínus seca (B) avaliadas no tempo (0 a 144 horas). 
O picão-preto indica ser mais sensível ao efeito alelopático da acícula de pínus se considerado o observado com a cultura do milho e da alface. Mostrando a possibilidade do uso de substâncias extraídas de acículas de pínus, quando ainda verde, para o controle de plantas daninhas, nesse caso o picão. Souza Filho (2006), comparando a atividade alelopática de Calycophyllum spruceanum em diferentes plantas, observou também que o potencial alelopático variou em função da espécie receptora. No trabalho realizado por Ferreira e Áquila (2000), extrato aquoso de Crotalaria juncea L. não inibiu a germinação do picão-preto, mas a utilização de extrato aquoso de mucuna preta (Stilozobium aterrimum) reduziu a velocidade de germinação do picão-preto. Nestes resultados mostram que o picãopreto torna-se sensível apenas em grandes concentrações dos pressupostos extratos, assim concordando com os resultados observados.
Para a característica de velocidade de germinação, houve interação entre a concentração do EB e o tipo de acículas para milho e alface (Figura 2A). A velocidade de germinação das sementes de milho foi menor quanto maior a concentração do EB de acícula de pínus. Os resultados se ajustaram a um modelo quadrático de regressão para tratamentos com AS e linear negativo para AV (Figura 2A), com aumento da concentração do EB. Nesse sentido, a velocidade de germinação foi menor na presença do estrato de AV quando comparado ao de AS. Na AS os compostos alelopáticos foram liberados ou transformados no solo, já que a estrutura da planta utilizada para fazer o EB encontra-se em estágio inicial de degradação, pois a parte ativa da planta vai se modificando no solo, assim não afetando a velocidade de germinação das sementes de milho.
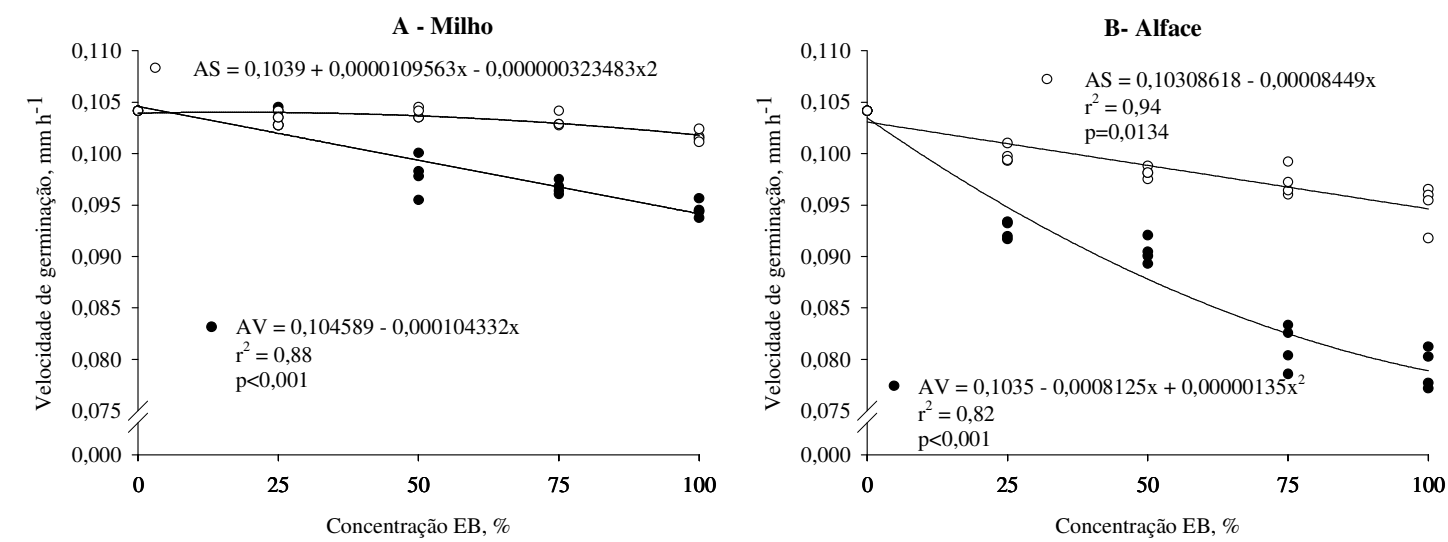

Figura 2. Velocidade de germinação de plântulas de milho (Figura 2A) e alface (Figura 2B) submetidas a concentrações $(0,25,50,75,100 \%)$ do extrato bruto (EB, \%) de acícula de pínus verde e acícula de pínus seca avaliadas no tempo ( 0 a 144 horas).

A alface apresentou ser mais sensível que o milho, comprovando a sua suscetibilidade perante o EB produzido a base de AV e AS de Pinus taeda. Com menor velocidade de germinação nos tratamentos com extrato a base de AV, quando comparado a AS. A velocidade de germinação reduziu com aumento da concentração do $\mathrm{EB}$, com maior efeito para AV (Figura 2B). Este resultado está de acordo com Soares (2000), que justifica a inibição da germinação da alface por extratos aquosos de espécies vegetais, como: pínus, eucaliptos, forrageiras, etc. O mesmo relata que um dos fatores importantes na queda da densidade de plântulas é a alelopatia. Pois muitas espécies de plantas, dentre elas o gênero Pinus ssp., liberam produtos do seu metabolismo secundário que podem impedir a germinação e/ou o desenvolvimento de outras plantas relativamente próximas. Também concordando com Ferreira et al. (2007), que encontrou em seus resultados, atraso da germinação e no crescimento inicial da alface em extratos vegetais de pínus.

A velocidade de germinação do picão-preto não apresentou influência dos fatores estágio de acícula, com média de $0,08610 \pm 0,0033 \mathrm{~mm} \mathrm{~h}^{-1}$. Ferreira et al. (2007) e Ferreira e Aquila (2000) concluíram que o picão-preto não possui seletividade na germinação, afirmando que o mesmo é de fato uma planta daninha.

Para a variável comprimento de radícula observou-se interação entre concentração do EB e o tempo de avaliação para o comprimento de radícula de plântulas de milho (Figura 3A). Quanto maior foi a concentração do EB, menor foi o desenvolvimento da radícula de plântulas de milho. As concentrações feitas a base de AS apresentaram os maiores 
comprimentos da radícula, com médias aproximadas 3,8 cm após 96 horas de avaliação. $\mathrm{O}$ atraso na germinação pode ter caracterizado esse efeito.

Também para o comprimento de radículas de plântulas de milho, houve interação entre estágio de acícula de pínus e o tempo de avaliação (Figura 3B). O comprimento de radícula, nesse caso, submetida à EB de AV ajustou-se a uma equação quadrática com menor desenvolvimento quando comparado ao desenvolvimento da radícula das plântulas em AS, ajustando-se a uma equação linear positiva. Ainda para comprimento de radícula de plântulas de milho, foi observada interação entre estágio de acícula de pínus e a concentração do EB (Figura 3C). Resultados que concordam com Faria et al. (2009) ao verificarem a redução do comprimento de radícula e hipocótilo de plântulas de milho com aumento da concentração do extrato aquoso de acículas pínus verde.

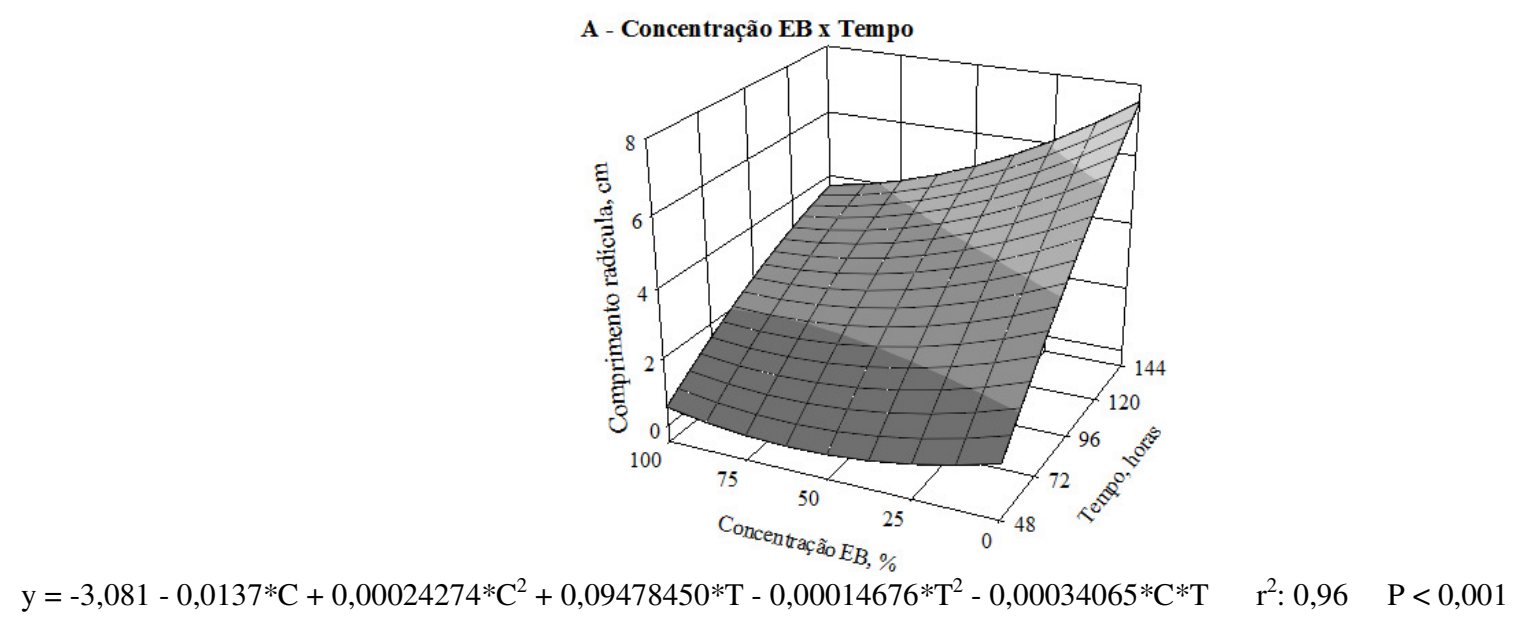

B - Estágio de Acícula x Tempo

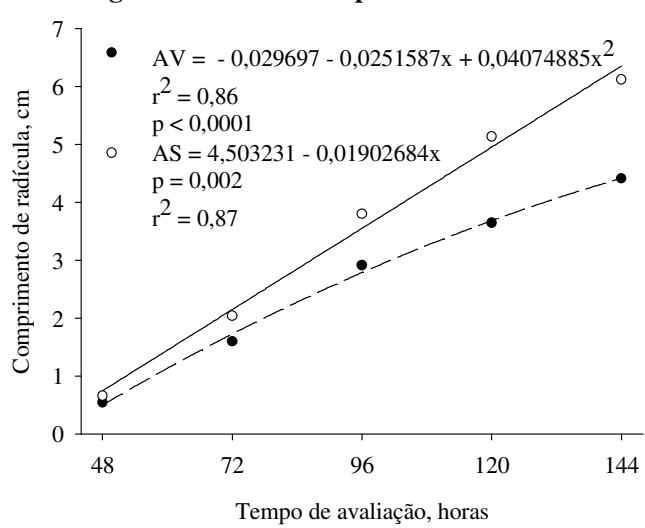

C - Estágio de Acícula x Concentração EB

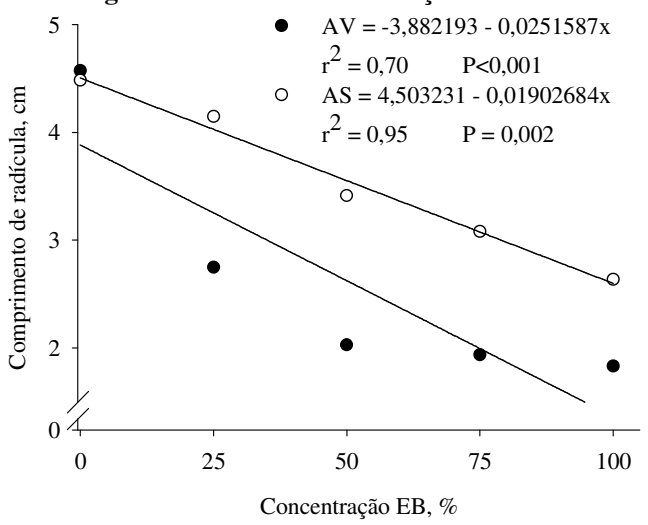

Figura 3. Comprimento da radícula de plântulas de milho $(\mathrm{cm})$ submetidas a concentrações $(0,25,50,75$, $100 \%)$ do extrato bruto (EB, \%) de acícula de pínus verde e acícula de pínus seca avaliadas no tempo (0 a 144 horas).

No geral, as sementes das plântulas avaliadas, em contato com as diferentes concentrações do EB feito a base de AV apresentaram menores desenvolvimento da radícula, quando comparadas às concentrações feitas base de AS. Concordando com Jacobi e Fleck (2000) por caracterizar o efeito alelopático inibitório pronunciado nas raízes submetidas a concentrações de extrato AV de Pinus taeda.

Quanto ao comprimento da radícula, foram observados efeitos prejudiciais, principalmente no tratamento com AV para alface e picão onde a inibição do crescimento radicular foi mais evidente. Com aumento da concentração do EB, menor o comprimento da radícula e mais pronunciado no tratamento AV. Malheiros e Peres (2001) mostraram que a quantidade de compostos aleloquímicos se dá em função da fitomassa das plantas, bem como da concentração e solubilidade de um dado aleloquímico, originando os compostos de forma ativa. Nesse contexto, substâncias alelopáticas podem induzir o aparecimento de plântulas anormais, sendo a necrose da radícula um dos sintomas mais comuns (Ferreira e Áquila, 2000). 
Houve interação tripla entre estágio de acícula e a concentração do EB e o tempo de avaliação para comprimento de radícula de alface (Figura 4). Para tal caracterizou-se menor comprimento radicular quando semeadas nos extratos contendo concentrações de AV de pínus. Contudo, com menor efeito para as sementes submetidas ao extrato com AS de Pínus taeda. Para ambos os tratamentos, quanto maior a concentração do EB, menor o crescimento das radículas. Concordando com Oliveira et al. (2004), onde concluíram que partes vegetativas de espécies de

A - Acícula verde

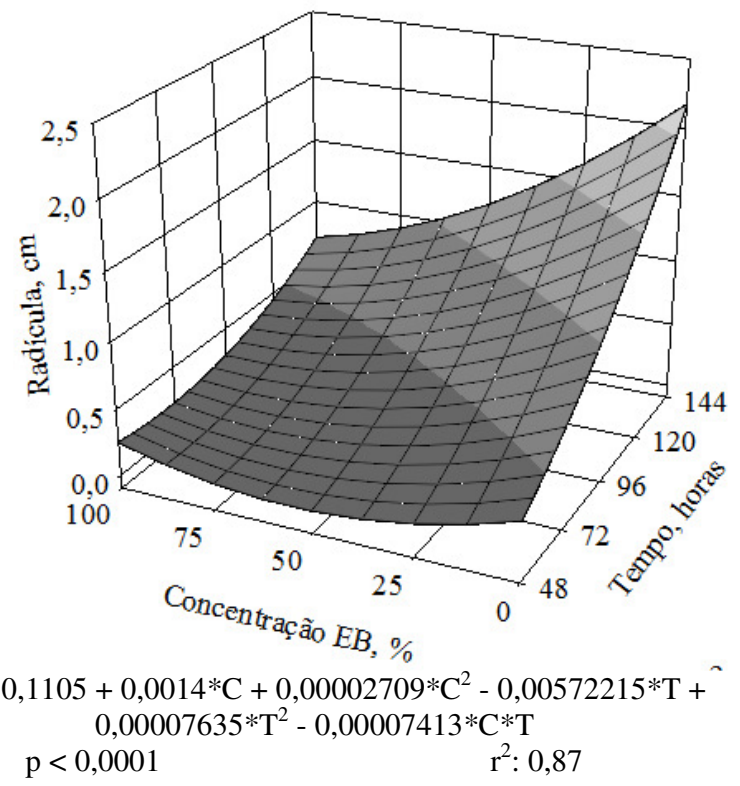

pínus e eucaliptos interferem no desenvolvimento final da alface, sob diferentes temperaturas ambientais. Compostos químicos extraídos das folhas de pínus também podem atingir diretamente a germinação das plantas vizinhas e esses extratos causam a redução significativa no desenvolvimento de suas raízes. Dessa maneira, percebe-se que folhas de pínus exercem efeitos inibitórios sobre espécies em estágios iniciais. Esse efeito dificulta o processo de restauração e diminui as chances da planta, nesse caso a alface, de voltar ao seu estado natural.

\section{B - Acícula seca}

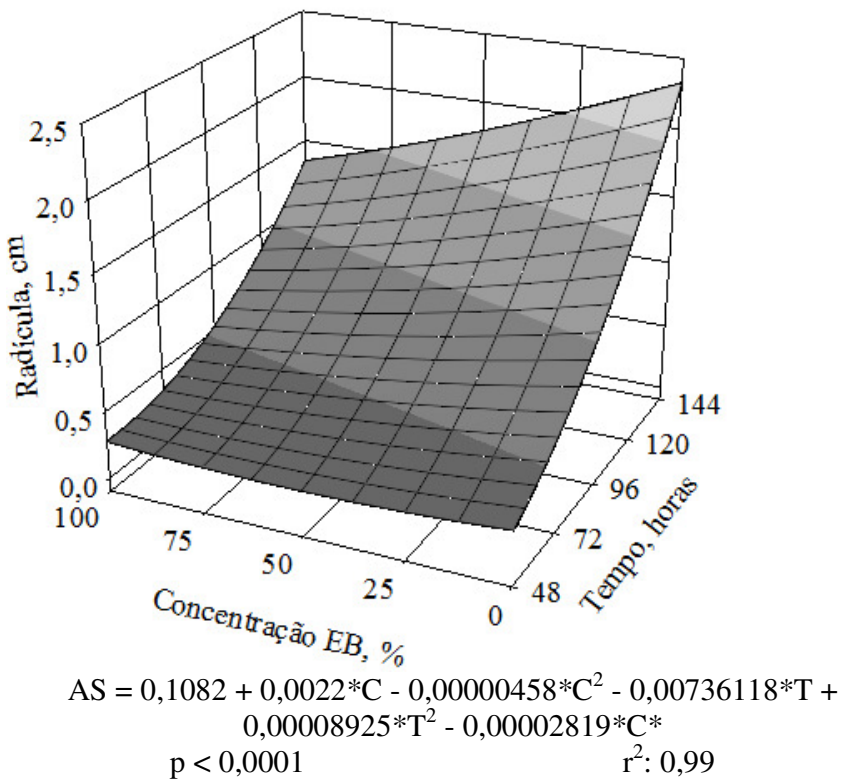

Figura 4. Comprimento da radícula de plântulas de alface submetidas a concentrações $(0,25,50,75,100 \%)$ do extrato bruto $(\mathrm{EB}, \%)$ de acícula de pínus verde (A) e acícula de pínus seca (B) avaliadas no tempo (0 a 144 horas).

Para picão-preto, o extrato aquoso de AV feita a base de Pínus taeda reduziu significativamente o tamanho das radículas, prejudicando o desenvolvimento das plântulas. Durante a avaliação, observaram-se diferenças significativas entre os tratamentos já nas primeiras 48 horas, onde o tamanho das radículas de picãopreto foi prejudicado na maior concentração do EB feito a base de AV. Assim mostrando que compostos do EB de Pínus taeda têm potencial de combate alelopático contra picão-preto.

$\mathrm{O}$ EB de AV causou atraso significativo na germinação nas concentrações testadas quando comparadas com a testemunha, já que o efeito alelopático também pode ocorrer sobre a velocidade de germinação e provocar alterações na curva de distribuição da germinação. O maior comprimento de epicótilo foi observado nas concentrações de $0 \%$ do EB (apenas com água destilada), diminuindo à medida que aumentava a concentração dos extratos. Visto que, por apresentar compostos alelopáticos, a AV de Pínus taeda pode servir como alternativa para controle de plantas, da mesma forma como acícula seca não apresenta efeitos pronunciados. Já AS podem servir como fonte de substrato para cultivo de plantas, mesmo porque se encontra com pouca atividade metabólica e diminuindo cada vez mais com o tempo até entrar no estágio degradativo.

$\mathrm{O}$ resultado encontrado mostrou que o comprimento do epicótilo de plântulas de milho gerou uma superfície de resposta, onde se observou que há interação entre concentração do estrato bruto e o tempo de avaliação para o comprimento do epicótilo do milho (Figura 5). Ferreira et al. (2007) encontraram resultados semelhantes, justificando que a partir de certo tempo depois de germinada 
(variando de acordo com a espécie vegetal), as plantas encontram-se mais resistentes a efeitos alelopáticos em diferentes concentrações. Também

A - Acícula verde

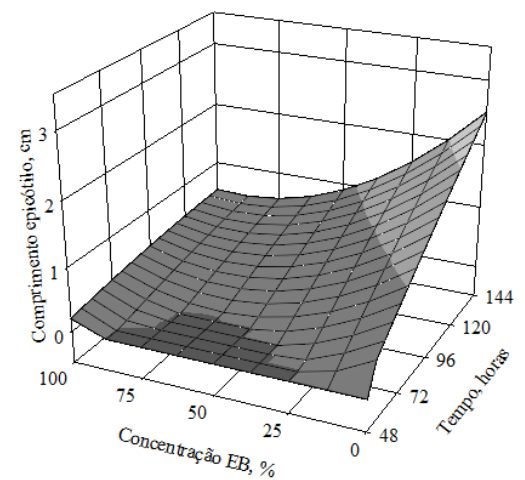

$\mathrm{AV}=-0,960-0,016 * \mathrm{C}+0,00024858 * \mathrm{C}^{2}+0,02703072 * \mathrm{~T}-$ $0,00002029 * \mathrm{~T}^{2}-0,00019849 * \mathrm{C} * \mathrm{~T}$ $\mathrm{p}<0,001$ $r^{2}: 0,86$

\section{A - Acícula verde}

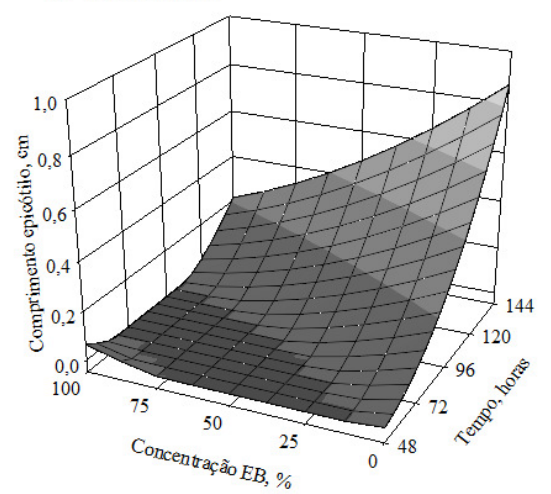

$\mathrm{AV}=0,0058-0,0033 * \mathrm{C}+0,00009239 * \mathrm{C}^{2}+0,00327451 * \mathrm{~T}+$ $0,00008181 * \mathrm{~T}^{2}-0,0001436 * \mathrm{C} * \mathrm{~T}$ $\mathrm{p}<0,0001$ $r^{2}: 0,94$ levando em consideração o tempo de vida/maturidade da planta.

\section{MILHO}

B - Acícula seca

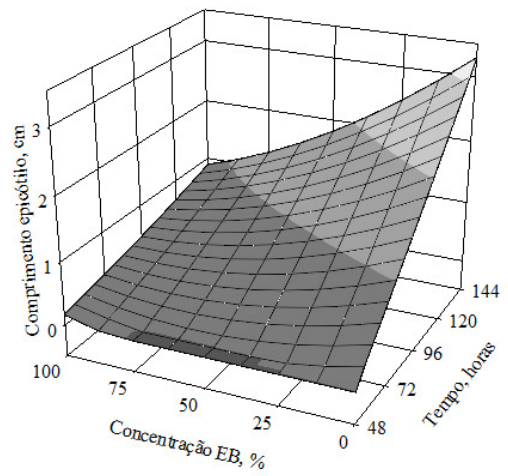

$\mathrm{AS}=-1,438+0,00278 * \mathrm{C}+0,0001107 * \mathrm{C}^{2}+0,03000104 * \mathrm{~T}-$ $0,00001970 * \mathrm{~T}^{2}-0,00026313 * \mathrm{C} * \mathrm{~T}$ $\mathrm{p}<0,001$

ALFACE

$$
\text { B - Acícula seca }
$$

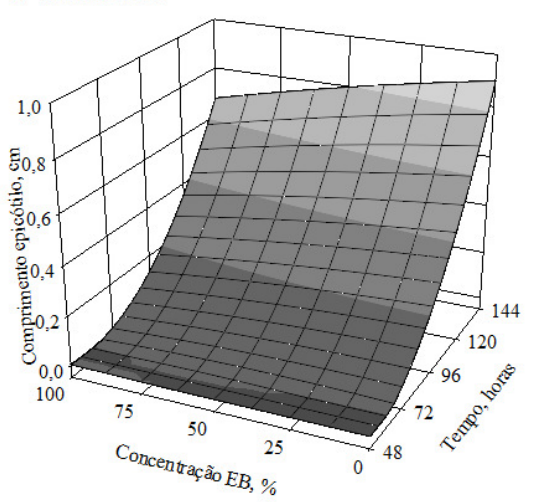

AS $=0,1191+0,0024 * \mathrm{C}+0,00002081 * \mathrm{C}^{2}-0,00175485 * \mathrm{~T}$ $+0,0001187 * \mathrm{~T}^{2}-0,00010021 * \mathrm{C} * \mathrm{~T}$ $\mathrm{p}<0,0001$

$$
\mathrm{r}^{2}: 0,94
$$

\section{PICÃO-PRETO}

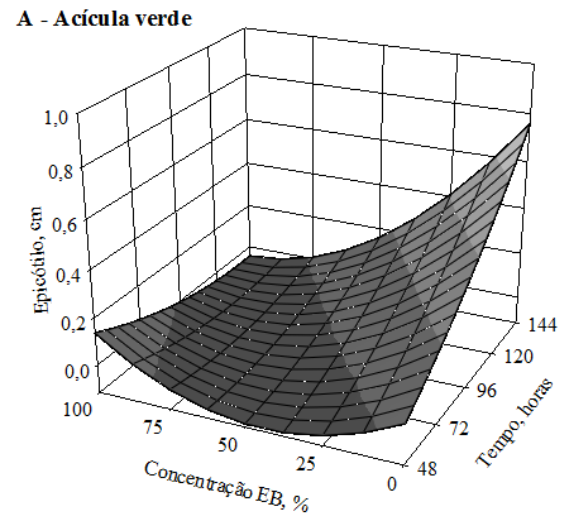

$\mathrm{AV}=-0,147-0,0026 * \mathrm{C}+0,00007937 * \mathrm{C}^{2}+0,00304965 * \mathrm{~T}+$ $0,00002241 * \mathrm{~T}^{2}-0,00009249 * \mathrm{C} * \mathrm{~T}$ $\mathrm{p}<0,0001$

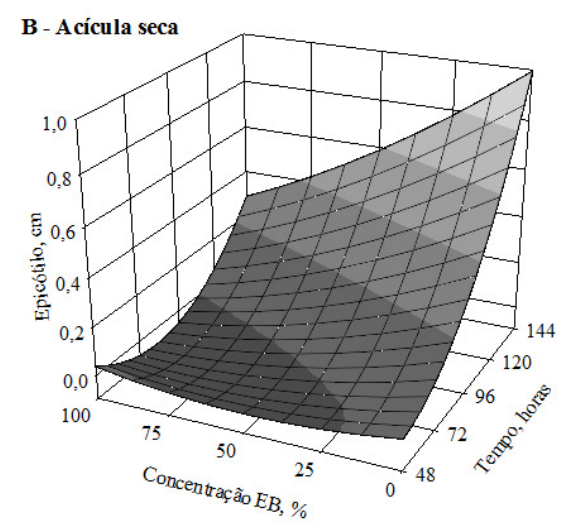

$\mathrm{AS}=0,192+0,0015 * \mathrm{C}+0,00002080 * \mathrm{C}^{2}$ $-0,00782862 * \mathrm{~T}+0,00009306 * \mathrm{~T}^{2}-0,00007458 * \mathrm{C} *$ $\mathrm{p}<0,0001$ $r^{2}: 0,72$

Figura 5. Comprimento do epicótilo de plântulas de milho, alface e picão-preto submetidas a concentrações $(0$, $25,50,75,100 \%)$ do extrato bruto $(\mathrm{EB}, \%)$ de acícula de pínus verde (A) e acícula de pínus seca (B) avaliadas no tempo (0 a 144 horas). 
O comprimento do epicótilo e da radícula pode estar relacionado com o aumento da concentração do EB feito a base de acícula de pínus, ou seja, os efeitos são mais visíveis nas maiores porcentagens do $\mathrm{EB}$, causando assim um retardo e/ou inibição no crescimento do epicótilo e da radícula. Concordando com Rezende et al. (2003) onde afirmam que as estruturas das plantas também sobrem efeitos alelopáticos produzidos por partes verdes de outras plantas, sendo da mesma espécie ou não.

Observou-se influência da interação tripla (Figura 5). Na testemunha (água destilada) o epicótilo das plântulas de alface iniciou o crescimento 48 horas após a semeadura. Já em extrato com AV era mais tardio o início do crescimento, quanto maior a concentração do EB. Uma vez que na concentração de $100 \%$ do EB o início do crescimento do epicótilo se deu 96 horas após a semeadura das sementes de alface no extrato de acícula verde de pínus. Contudo, no extrato de AS de pínus, entre 48 e 72 horas todas as plântulas de alface apresentavam algum desenvolvimento da radícula e do epicótilo.

Da mesma forma que para porcentagem de germinação de sementes de picão, o comprimento de epicótilo dessa espécie vegetal teve efeito da interação tripla (Figura 5). Para essa variável o efeito do extrato de AV de pínus foi mais pronunciado que para porcentagem de germinação, sendo observado atraso na emissão do epicótilo com aumento da concentração do EB e sem desenvolvimento do mesmo no tempo de 144 horas avaliado na concentração de $100 \%$ do EB.

Houve diferença significativa entre as concentrações feita à base de $\mathrm{EB}$ com $\mathrm{AV}$, onde mostrou que houve inibição no crescimento do epicótilo das culturas testadas. Segundo Pires et al. (2001), os extratos feitos à base de AV possuem efeitos mais acentuados na alface e em outras plantas sensíveis a alelopatia, pelo fato dos compostos voláteis estarem mais presentes (recentes nas folhas). Mesmo porque, fazem parte dos diferentes processos metabólicos secundários, onde são ativados a partir de estímulos, internos ou externos, tendo como resultado uma série de eventos coordenados a nível celular por um complexo de sinais, já que a comunicação entre os órgãos é estabelecida por mensagens químicas, chamadas hormônios ou fitormonios. Portanto, a acícula de pínus quanto verde apresenta compostos alelopáticos que podem vir a serem extraídos a fim do controle biológico de plantas daninhas.

\section{CONCLUSÕES}

A germinação, o comprimento de radícula e de epicótilo e a velocidade germinação milho, picão preto e alface são afetadas quando cultivadas na presença de extrato aquoso de acículas de Pinus taeda.

Extrato aquoso de acículas verde apresenta maior efeito em relação ao de acículas secas, principalmente nas maiores concentrações do extrato.

\footnotetext{
ABSTRACT: Agrosilvipastoris systems are expanding the spaces occupied and gaining new adherents in order expansions productive in the same areas. But some issues, such as allelopathic effects of some cultures, in which case the pine, are still poorly known. This research aimed to evaluate the allelopathic effect of aqueous extract from the pine needles on the germination and development of lettuce, corn and beggarticks seedlings. The experiment was carried in a completely randomized design with treatments arranged in a factorial (2x5), where: conditions of the needles (green and dry) $\mathrm{x}$ extracts concentrations $(0,25,50,75$ and $100 \%)$ in four replications, under temperature, humidity and light controlled. Evaluations were carried out time intervals of 24 hours, from 0 to 144 hours. It was evaluated the germination, average speed of germination, the length of the primary roots of lettuce and the length from the seedlings roots of lettuce, beggarticks and corn. Extracts the base of green needles affected the variables, where the effect increased with increase in concentration, the effect being more marked in beggarticks. In the statement the basis of dry pine needles, there were minimal results when compared to control.
}

KEYWORDS: Bidens pilosa. Lactuca sativa. Pinus taeda. Zea mays.

\section{REFERÊNCIAS}

ALVES, M. C. S.; MEDEIROS FILHO, S.; INNECCO, R.; TORRES, S. B. Alelopatia de extratos voláteis na germinação de sementes e no comprimento da raiz de alface. Pesquisa Agropecuária Brasileira, Brasília, v. 39, n. 11, p. 1083-1086, 2004. http://dx.doi.org/10.1590/S0100-204X2004001100005 
BRASIL. Regras para análise de sementes. Brasília: SNDA/DNDV/CLAV, Ministério da Agricultura e Reforma Agrária, 1992.365p.

EMBRAPA. Ambiente de software NTIA, versão 4.2.2: manual do usuário - ferramental estatístico. Centro Nacional de Pesquisa Tecnológica em Informática para a Agricultura. Campinas, 258p, 1997.

EMPRESA BRASILEIRA DE PESQUISA AGROPECUÁRIA - EMBRAPA. Sistema Brasileiro de Classificação de Solos. Rio de Janeiro: 2006, 412p.

ERASMO, E. A. L.; AZEVEDO, W. R.; SARMENTO, R. A.; CUNHA, A. M.; GARCIA, S. L. R. Potencial de espécies utilizadas como adubo verde no manejo integrado de plantas daninhas. Planta Daninha, Viçosa, v. 22, n. 3, p. 337-342, 2004.

FARIA, T. M.; GOMES JUNIOR, F. G.; SÁ, M. E.; CASSIOLATO, A. M. R. Efeitos alelopáticos de extratos vegetais na germinação, colonização micorrízica e cresimento inicial de milho, soja e feijão. Revista Brasileira de Ciência do Solo, Viçosa, v. 33, p. 1625-1633, 2009.

FAVERO, C.; JUCKSCH, I.; ALVARENGA, R. C.; COSTA, L. M. Modificações na população de plantas espontâneas na presença de adubos verdes. Pesquisa Agropecuária Brasileira, Brasília, v. 36, n. 11, p. 13551362, 2001. http://dx.doi.org/10.1590/S0100-204X2001001100005

FERREIRA, A. G.; AQUILA, M. E. A. Alelopatia: uma área emergente da ecofisiologia vegetal. Revista Brasileira de Fisiologia Vegetal, Campinas, v. 12, n. 1, p. 175-204, 2000.

FERREIRA, M. C.; SOUSA, J. R. P.; FARIA, T. J. Potenciação alelopática de extratos vegetais na germinação e no crescimento inicial de picão preto e alface. Ciência e Agrotecnologia, Lavras, v. 31, n. 4, p. 1054-1060, 2007.

FORMAGIO, A. S.; MASSETO, T. E.; VIEIRA, C. M.; ZARATÉ, N. A. H.; COSTA, W. F.; TREVISAN, L. N. F.; SARAGIOTO, M. H. Potencial alelopático de Tropaeolum majus L. na germinação e crescimento inicial de plântulas de picão-preto. Ciência Rural, Santa Maria, v. 42, n. 1, p. 83-89, 2011.

http://dx.doi.org/10.1590/S0103-84782012000100014

http://dx.doi.org/10.1590/S0103-84782011005000148

GATTI, A. B.; PEREZ, S. C. J. G. A.; LIMA, M. I. S. Atividade alelopática de extratos aquosos de Aristolochia esperanzae O. Kuntze na germinação e no crescimento de Lactuca sativa L. e Raphanus sativus L. Acta Botânica Brasilica, Belo Horizonte, v. 18, n. 3, p. 459-472, 2004. http://dx.doi.org/10.1590/S010233062004000300006

GRISI, P. U.; RANAL, M. A.; GUALTIERI, S. C. J.; SANTANA, D. G. Allelopathic potential of Sapindus saponaria L. leaves in the control of weeds. Acta Scientiarum Agronomy, Maringá, v. 34, n. 1, p. 1-9, 2012.

INOUE, M. H.; SANTANA, D. C.; SOUZA FILHO, A. P. S.; POSSAMAI, A. C. S.; SILVA, L. E.; PEREIRA, M. J. B.; PEREIRA, K. M. Potencial alelopático de Annona crassiflora: efeitos sobre plantas daninhas. Planta Daninha, Viçosa, v. 28, n. 3, p. 489-498, 2010.

JACOBI, U. S.; FLECK, N. G. Avaliação do potencial alelopático de genótipos de aveia no início do ciclo. Pesquisa Agropecuária Brasileira, Brasília, v. 35, v. 1, p. 11-19, 2000.

LABOURIAU, L. G.; VALADARES, M. B. On the germination of seeds of Calotropis procera. Anais da Academia Brasileira de Ciências, Rio de Janeiro, v. 48, n. 1, p. 263-284, 1976.

MALHEIROS, A; PERES M. T. L. P. Alelopatia: interações químicas entre espécies. In: YUNES, R. A; CALIXTO, J.B. Plantas medicinais sob a ótica da química medicinal moderna. Chapecó: Argos, p. 503523, 2001. 
MAULI. M. M. et al. Alelopatia de Leucena sobre soja e plantas invasoras. Semina, Londrina, v. 30, n. 1, p. 55-62, 2009.

MORENO, J. A. Clima do Rio Grande do Sul. Porto Alegre: Secretaria da Agricultura, 1961. 41p.

OLIVEIRA, S. C. C., FERREIRA, A. G., BORGHETTI, F. Efeito alelopático de folhas de Solanum lycocarpum A. St. Hil. (Solanaceae) na germinação e crescimento de Sesamum indicum L. (Pedaliaceae) sob diferentes temperaturas. Acta Botânica Brasílica, Belo Horizonte, p. 401-406. 2004.

PIRES, N. M. et al. Atividade alelopática da leucena sobre espécies de plantas daninhas. Scientia Agrícola, Piracicaba, v. 58, n. 1, p. 61-65, 2001.

REZENDE, C. P. Alelopatia e suas interações na formação e manejo de pastagens. Boletim Agropecuário: Lavras, n. 54, p. 1-55, 2003.

RIZZARDI, A.; RIZZARDI, M. A., LAMB, T. D.; JOHANN, L. B. Potencial alelopático de extratos aquosos de genótipos de canola sobre Bidens pilosa. Planta Daninha, Viçosa, v. 26, n. 4, p. 717-724, 2008.

SARTOR, L. R.; ADAMI, P. F.; CHINI, N.; MARTIN, T. N.; MARCHESE, J. A.; SOARES, A. B. Alelopatia de acículas de Pinus taeda na germinação e no desenvolvimento de plântulas de Avena strigosa. Ciência Rural, Santa Maria, v. 39, n. 6, p. 1553-1559, 2009. http://dx.doi.org/10.1590/S0103-84782009000600004

SILVA, R. M, G.; SANTOS, V. H. M.; BORGES, F. M. B.; MELO, F. F. Q. Potencial alelopático e levantamento do banco natural. Bioscience Journal, Uberlândia, v. 28, n. 4, p. 641-653, 2012.

SILVEIRA, P. F.;MAIA, S. S. S.; COELHO, M. F. B. Potencial alelopático do extrato aquoso de folhas de Mimosa tenuiflora (Willd.) Poir. na germinação de Lactuca sativa L. Bioscience Journal, Uberlândia, v. 28, n. 3, p. 472-477, 2012.

SOARES, G. L. G. Inibição da germinação e do crescimento radicular de alface (cv. 'Grand Rapids') por extratos aquosos de cinco espécies de Gleicheniaceae. Floresta e Ambiente, Rio de Janeiro, v. 7, n. 1, p. 190197, 2000.

SOUZA FILHO, A. P. S. Plantas arbóreas e arbustivas com atividade alelopática. In: SOUZA FILHO, A. P. S. Alelopatia e as Plantas. Belém: Embrapa, 2006. p. 59-76.

SOUZA FILHO, A. P. S.; GURGEL, E. S. C; QUEIROZ, M. S. M; SANTOS, J. U. M. Atividade alelopática de extratos brutos de três espécies de Copaifera (Leguminosae - Caesalpinioideae). Planta daninha, Viçosa, v. 28, n. 4, p. 743-751, 2010. 